\title{
Desensitization of $\beta$-Receptor Mediated Responses to Epinephrine in Fetal Lambs by Prolonged Ritodrine Administration
}

\author{
J. M. BASSETT, C. M. WEEDING, AND C. HANSON \\ University of Oxford, Growth and Development Unit, University Field Laboratory, Wytham, \\ Oxford, OX2 8RJ, England
}

\begin{abstract}
During prolonged administration of $\beta$-agonists such as ritodrine directly to chronically cannulated fetal lambs, the cardiovascular, metabolic, and endocrine changes observed during the 1st day of administration, lessen and return to normal within 3-4 d despite continuing drug administration. In our investigation, heart rate, plasma FFA, lactate, glucose, and insulin concentrations all increased significantly during the 1 st day of ritodrine infusion $(10 \mu \mathrm{g} / \mathrm{min})$, whereas blood $\mathrm{PO}_{2}$ and base excess were significantly decreased. After 3 d, despite continued drug infusion, all these changes had ameliorated. To examine the hypothesis that this tachyphylaxis to ritodrine also results in decreased sensitivity to endogenous catecholamines, epinephrine $(1 \mu \mathrm{g} / \mathrm{min}$ i.v. for $60 \mathrm{~min}$, then 2 $\mu \mathrm{g} / \mathrm{min}$ i.v. for a further $60 \mathrm{~min}$ ) was infused into fetal lambs (124-130 d gestation) $1 \mathrm{~d}$ before, then $5 \pm 1 \mathrm{~d}$ after, and again $10 \pm 1 \mathrm{~d}$ after beginning ritodrine infusion. Before ritodrine administration, epinephrine significantly increased plasma FFA, lactate, glucose, and glucagon concentrations and decreased insulin. However, after ritodrine treatment for either $5 \pm 1$ or $10 \pm 1 \mathrm{~d}$, epinephrine resulted in no significant increases in FFA or glucagon, and those in lactate and glucose were significantly reduced. Decreases in insulin during epinephrine administration were unchanged by ritodrine. Initial responses of mean arterial pressure and heart rate to epinephrine were significantly greater during prolonged ritodrine treatment. Fetal responses to epinephrine mediated through $\beta$-adrenergic receptor mechanisms were clearly decreased when administration of $\beta$-agonists was prolonged beyond $24 \mathrm{~h}$. (Pediatr Res 28: 388-393, 1990)
\end{abstract}

$\beta$-adrenergic drugs have been widely used for prophylaxis of threatened premature labor in women, but it is known that they cross the placenta readily and influence the fetal heart rate as well as that of the mother in the early stages of treatment (1). Despite this, there have been few investigations in which any other effects on the fetus have been determined during prolonged administration $(2,3)$. In the sheep, ritodrine crosses the placenta less readily (4), so fetal responses to maternal ritodrine infusion (5) may not reflect direct actions of the drug on the fetus. We have shown, however, that prolonged administration of ritodrine to fetal sheep at rates comparable to those used for tocolysis (6) results in major metabolic, endocrine, and physiologic changes

Received September 25, 1989; accepted April 27, 1990.

Correspondence and reprint requests: John M. Bassett, Ph.D., The Growth and Development Unit, University Field Laboratory, Wytham, Oxford, OX2 8QJ, England.

Supported by a project grant from the Agricultural and Food Research Council of Great Britain (C.M.W.). typical of prolonged stimulation of $\beta$-adrenergic receptor mechanisms. Hyperglycemia, hyperlactacidemia, and hyperinsulinemia occur and acid-base balance is severely taxed during the 1st 48-72 h of infusion. Further, Warburton et al. (7) have observed that the hyperglycemia is associated with substantial depletion of hepatic glycogen reserves after $24 \mathrm{~h}$ administration. Also, both we (6) and Warburton et al. (8) have shown that administration of ritodrine for $24 \mathrm{~h}$ or longer results in the development of marked hypoxemia at least as severe as that seen in fetal lambs during prolonged hyperglycemia and/or hyperinsulinemia ( 9 , 10). After administration of the drug for more than $48 \mathrm{~h}$, these changes moderate (6). It appears that it is only the development of tachyphylaxis to the drug that permits the restoration of homeostasis during more prolonged administration. Indeed, Warburton et al. $(11,12)$ have shown that there is already a very marked reduction in the $\beta$-adrenergic receptor population of fetal lung tissue after $24 \mathrm{~h}$ of ritodrine administration. More widespread changes in sensitivity of $\beta$-adrenergic receptor mechanisms have not been investigated.

Although this reduction in sensitivity may permit fetal survival in the face of prolonged ritodrine treatment, we questioned whether it might have other less desirable consequences in view of the importance of $\beta$-adrenergic receptor mechanisms for perinatal adaptation $(5,6)$. In our study, we have investigated effects of prolonged ritodrine administration to fetal lambs on a number of well-characterized metabolic, endocrine, and cardiovascular responses to a standard test infusion of epinephrine (13-16) to assess further how the drug may influence responsiveness to physiologic elevation of adrenal catecholamine release.

\section{MATERIALS AND METHODS}

Animals and their preparation. Pregnant Mule $\times$ Suffolk crossbred sheep, body weight $65.8 \pm 4.3 \mathrm{~kg}$ (mean $\pm \mathrm{SD} ; n=10$ ), mated with Polled Dorset rams and of accurately known gestational age, were used in the studies. Until operation at 117-123 $\mathrm{d}$ gestation (term is $147 \mathrm{~d}$ ) they were maintained either at pasture or in a sheep barn where they were fed hay ad libitum. The number of fetuses was determined by real-time ultrasound scanning at 60-80 d gestation using a Real-time XPL 1 Medical Scanner (Dynamic Imaging Ltd., Livingston, Scotland, UK). Three of the ewes carried a single fetus, eight carried twin fetuses, and one, triplets. At surgery, using procedures similar to those described previously (17), all single and twin fetuses were cannulated, but only two of the triplets were cannulated. Anesthesia was induced using $10 \%$ thiopentone and maintained with halothane and oxygen. A $2.0-\mathrm{mm}$ single lumen catheter was placed in one femoral artery and a $2.0-\mathrm{mm}$ triple lumen catheter into a femoral vein of each fetus, and 3-mm catheters were placed in the left jugular vein and carotid artery of the ewe. An additional $3.0-\mathrm{mm}$ catheter with several side holes near the tip was sewn to the skin of each fetus to permit sampling of amniotic fluid and 
measurement of amniotic fluid pressure. Ewes were standing and eating within 1-2 $\mathrm{h}$ of the end of surgery. Ewes were given $1 \mathrm{~g}$ procaine penicillin and $1 \mathrm{~g}$ dihydrostreptomycin intramuscularly at surgery and daily for $4 \mathrm{~d}$ afterward; fetuses were given $300 \mathrm{mg}$ benzylpenicillin and $10 \mathrm{mg}$ gentamicin i.v. daily over the same period. After recovery from surgery, ewes were kept in metabolism cages for the duration of the experiments; they were offered water and hay ad libitum and $0.5 \mathrm{~kg}$ dried grass pellets twice daily. Catheters were flushed daily with heparin saline to maintain patency. Pressure transducers were connected to fetal arterial and amniotic catheters outside the cages to permit continuous monitoring of fetal arterial blood pressure and heart rate. Blood samples were collected before the morning feed to monitor fetal well-being and to determine metabolite and hormone levels.

Experiments. Infusions of ritodrine hydrochloride (Yutopar, Duphar Laboratories, Southampton, UK) into the fetuses were begun at $126 \pm 1.3 \mathrm{~d}$ gestation ( 7 or $8 \mathrm{~d}$ after operation) in 10 and at $137 \mathrm{~d}$ gestation ( $19 \mathrm{~d}$ after surgery) in one. The drug was diluted in sterile saline and infused at a rate of $10 \mu \mathrm{g} / 0.02 \mathrm{~mL}$. $\mathrm{min}^{-1}$ via one lumen of the femoral vein catheter. Infusions were continued for 12-14 d unless terminated by premature delivery. Blood samples were collected from the ewe and each fetus daily, before the morning feed, for determination of blood gases and metabolite and hormone concentrations. On the 1st day of ritodrine infusion, samples were collected at 2-h intervals for 8 h. To provide additional control information, regular blood samples were also obtained over a period of 6-10 d from a number of fetuses not infused with ritodrine (two were twins to ritodrine-treated fetuses and the others were involved primarily in a concurrent but unrelated investigation).

The effect of prolonged ritodrine infusion on the responsiveness of fetal lambs to endogenous catecholamines was examined by giving infusions of epinephrine lasting $2 \mathrm{~h}$ to eight fetuses via a separate lumen of their femoral vein catheter before and then again $5 \pm 1 \mathrm{~d}$ after starting ritodrine infusion, while ritodrine infusion continued uninterrupted. Five of these fetuses and two others not given epinephrine before were also given epinephrine $10 \pm 1 \mathrm{~d}$ after starting ritodrine treatment. During the 1 st hour, epinephrine (Adrenaline Injection, McCarthy Medical, Romford, Essex, UK), diluted in sterile saline containing $0.3 \%$ ascorbic acid, was infused at a rate of $1 \mu \mathrm{g} / \mathrm{min}(6 \mathrm{~mL} / \mathrm{h})$. During the 2 nd hour, the infusion rate was doubled to $12 \mathrm{~mL} / \mathrm{h}$. To provide some control for changes in response to epinephrine with increasing gestational age, similar epinephrine infusions were also given to eight other normal fetuses at gestational ages comparable to those of the ritodrine-treated fetuses. Samples of fetal and maternal blood were collected at intervals of $30 \mathrm{~min}$ before, during, and, where possible, after infusions of epinephrine. All blood samples were collected in heparinized syringes and transferred to centrifuge tubes on ice. Plasma was separated by centrifugation at $4^{\circ} \mathrm{C}$ as soon as possible after collection. Trasylol (500 kallikrein inhibitor units/mL blood) was added to all samples to minimize proteolysis. Plasma was stored at $-20^{\circ} \mathrm{C}$ until required for analysis.

Analysis. Mean fetal arterial pressure and heart rate were determined as in our previous report (6), average rates over 15 min periods being determined by hand from continuous records. Blood gases and $\mathrm{pH}$ were measured at $39^{\circ} \mathrm{C}$ using a Corning 168 $\mathrm{pH} /$ Blood Gas Analyser (Ciba Corning Medical, Halstead, Essex, UK). Hematocrits were determined using a microhematocrit centrifuge (Hawksley, Sussex, UK). Blood glucose, lactate, and the hormones insulin and glucagon were determined by methods reported previously $(5,6)$. FFA were determined on $100-\mu \mathrm{L}$ samples of fetal plasma by a microcolorimetric method using Wako NEFA kits (Alpha Laboratories, Fareham, Hants, UK) after first diluting both the reagents to half the recommended concentration.

Statistics. Hormone concentrations were converted to logarithms before calculation of means or other statistics, and results are presented graphically using log scales. The responses of control and ritodrine-treated fetuses to epinephrine during the 2 $\mathrm{h}$ of the infusion were compared by regression analysis where appropriate. Also, to provide a single value for fetal responses to epinephrine infusion, the means of eight observations of heart rate and five observations of plasma metabolite and hormone concentrations during the period $0-120 \mathrm{~min}$ of infusion were calculated. These values were then expressed as a percentage of the basal value during the control period before epinephrine infusion (i.e. a value equivalent to the integrated area under the response curve during epinephrine infusion). Comparisons between ritodrine-treated and control fetuses have been made by analysis of variance and the Student Newman-Keuls test. The significance of changes with time in the response to ritodrine has been assessed by two-way analysis of variance for unequal subclass numbers using sheep as blocks.

\section{RESULTS}

Ritodrine infusion was continued for $3 \mathrm{~d}$ in 11 fetuses, but in seven of them, infusion was continued for at least $10 \mathrm{~d}$. Infusions were terminated in the others by premature delivery. At the time of termination, the 11 ritodrine-treated fetuses weighed $3.61 \pm$ $0.86 \mathrm{~kg}$, whereas the 10 control fetuses weighed $3.42 \pm 0.70 \mathrm{~kg}$. All the fetuses remained healthy as assessed by measurements of blood gases and $\mathrm{pH}$. Changes in fetal blood gases, metabolites, and hormone concentrations during the $1 \mathrm{st} 72 \mathrm{~h}$ of ritodrine infusion (Table 1) were consistent with those reported earlier (6), but the longer duration of infusion in these lambs shows more clearly the complete return of all these parameters to the normal range within $4 \mathrm{~d}$, despite continued infusion of ritodrine (Table 1). Heart rate and the plasma concentrations of glucose, lactate, and insulin were all significantly increased after $24 \mathrm{~h}$ of ritodrine, whereas blood $\mathrm{PO}_{2}$ and base excess were significantly decreased. There was a small, just statistically significant increase in $\mathrm{PCO}_{2}$, but this did not occur in all fetuses. Despite the challenge to acid-base regulation, blood $\mathrm{pH}$ was not significantly reduced. Also, mean arterial pressure was unchanged. After ritodrine infusion for $1 \mathrm{wk}$, blood $\mathrm{PO}_{2}$ was apparently increased and $\mathrm{PCO}_{2}$ decreased compared with initial control values, but the effect was small. Hematocrit declined steadily from an initial control value of $33.6 \pm 4.15$ (11) to $27.5 \pm 2.70$ (7) after $10 \mathrm{~d}$ of infusion, but this change seemed related to the frequency of fetal blood sampling rather than to any effect of ritodrine.

Plasma FFA concentrations, not determined previously, show that fat mobilization is also greatly increased during the 1 st $48 \mathrm{~h}$ of ritodrine administration (Fig. 1), but then, like changes in plasma lactate and other metabolites measured, returns to the normal range. Three $\mathrm{d}$ after the start of infusion, however, fetal plasma FFA concentration is still significantly increased (Fig. 1).

Infusion of epinephrine for $2 \mathrm{~h}$ on the day before ritodrine infusion was begun resulted in metabolic and endocrine changes similar to those reported in earlier studies (13-16). Plasma FFA, lactate, glucose, and glucagon concentrations all increased significantly, whereas insulin concentrations decreased (Figs. 2 and 3 ). However, during prolonged ritodrine administration, whether for $5 \pm 1 \mathrm{~d}$ or $10 \pm 1 \mathrm{~d}$, responses to infusion of epinephrine were greatly altered, with responses mediated by $\beta$-adrenergic receptors being reduced or abolished, even during the 2 nd hour when the infusion rate was doubled. Regression analysis, used to determine whether there were significant increases in metabolites and hormone levels during epinephrine infusion, confirmed that there was no significant increase in FFA and only a minimal increase in lactate concentration in ritodrine-treated fetuses (Fig. 2). There was also no significant increase in glucagon as assessed by regression analysis in ritodrine-treated fetuses, whereas that in glucose was significantly less than in the control study $(p<$ 0.01) (Fig. 3). By contrast, the inhibition of insulin secretion was not altered (Fig. 3). Responses to epinephrine in other control fetuses not infused with ritodrine were in general directly comparable to those seen during the initial control studies. They were 
Table 1. Cardiovascular, metabolic, and endocrine changes in fetal lambs during prolonged administration of ritodrine (10 $\mu \mathrm{g} / \mathrm{min}$ ) directly to fetus in utero during last month of gestation

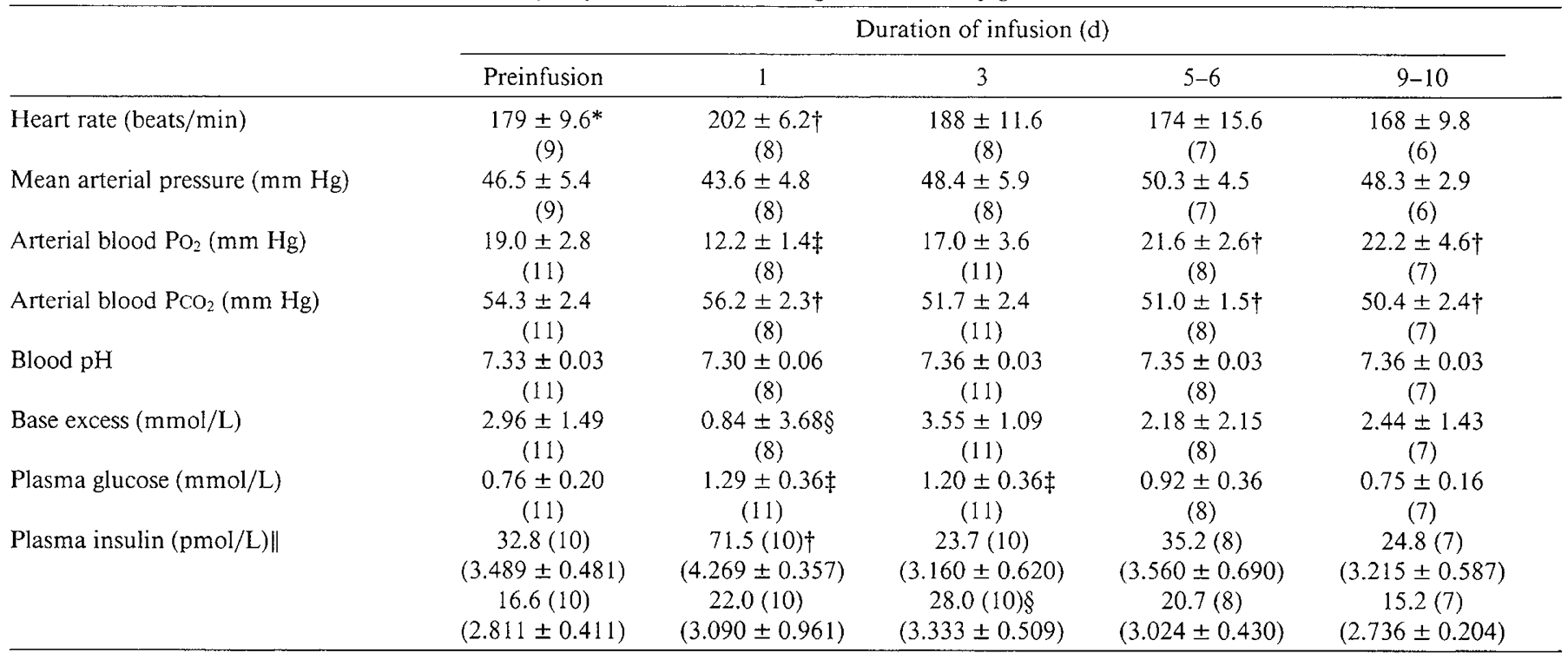

\footnotetext{
$*$ Mean $\pm \mathrm{SD}$.

$\dagger p<0.05$ compared with preinfusion control values as determined by analysis of variance.

$\ddagger p<0.001$ compared with preinfusion control values.

$\S p<0.01$ compared with preinfusion control values.

$\|$ Values are geometric means with $\ln$ values $\pm \mathrm{SD}$ in parentheses.
}
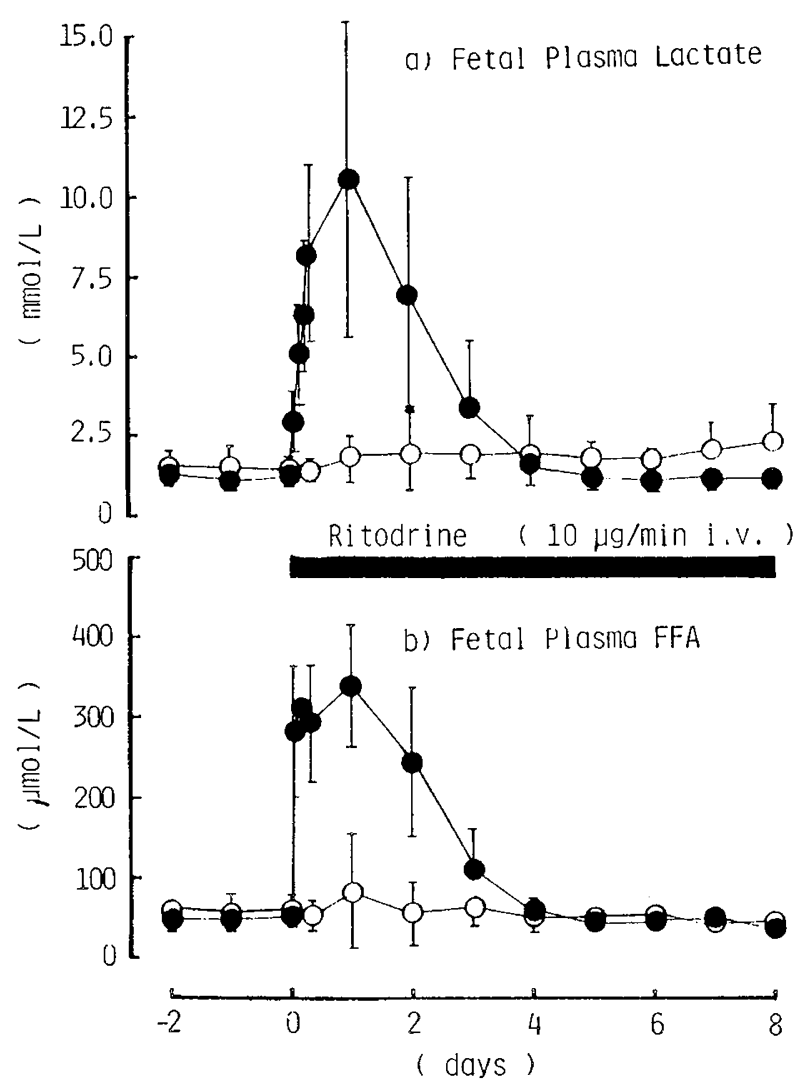

Fig. 1. Plasma lactate and FFA concentrations in 11 chronically cannulated fetal lambs given ritodrine $(10 \mu \mathrm{g} / \mathrm{min})$ by continuous i.v. infusion (-) compared with values in seven untreated control fetuses (O). Values shown are means \pm SD of 6-11 observations of the ritodrinetreated lambs and 4-7 values for the controls. (Four ritodrine-treated fetuses and two controls delivered prematurely on or after the 5th day.)

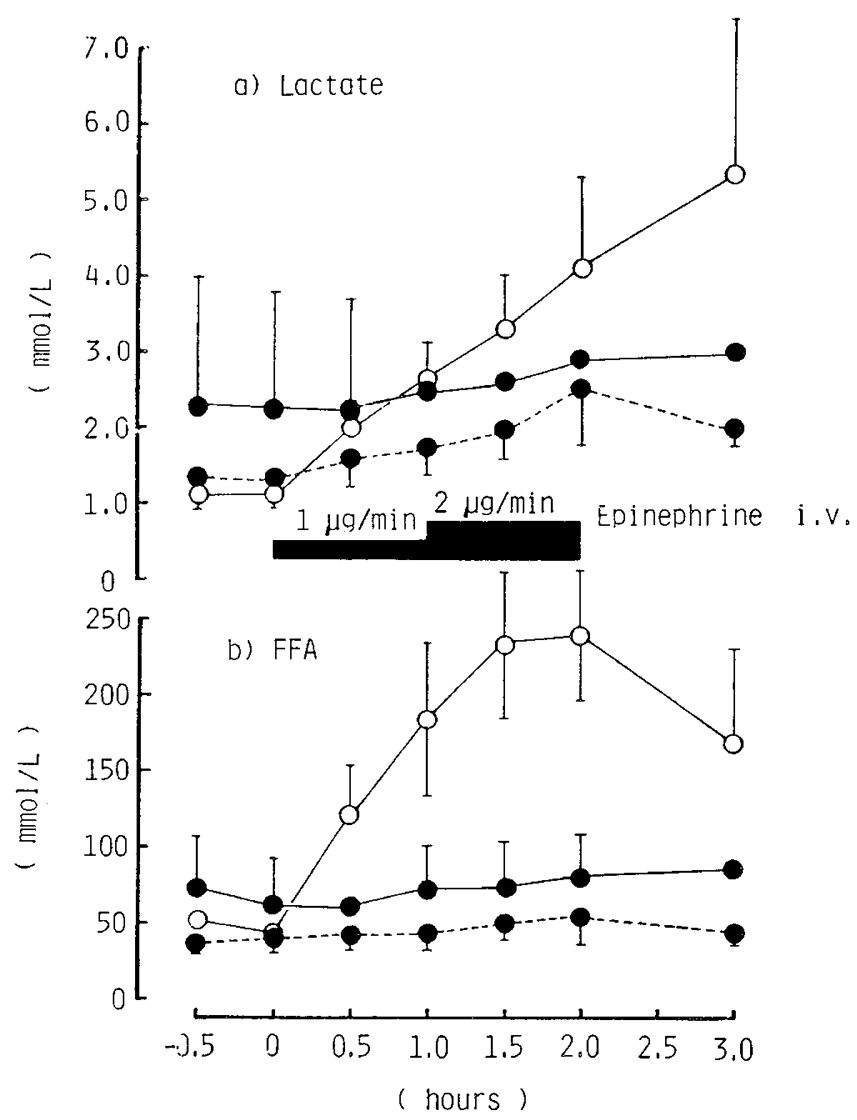

Fig. 2. The effect of i.v. epinephrine infusion on mean \pm SD plasma concentrations of $a$ ) lactate and $b$ ) FFA in chronically cannulated fetal lambs $24 \mathrm{~h}$ before $(\bigcirc-\mathrm{O} ; n=8)$, then $5 \pm 1 \mathrm{~d}$ after $(\longrightarrow ; n$ $=8)$, and again $10 \pm 1 \mathrm{~d}$ after $(-\cdots ; n=7)$ starting i.v. ritodrine infusion $(10 \mu \mathrm{g} / \mathrm{min})$ to the fetus. 


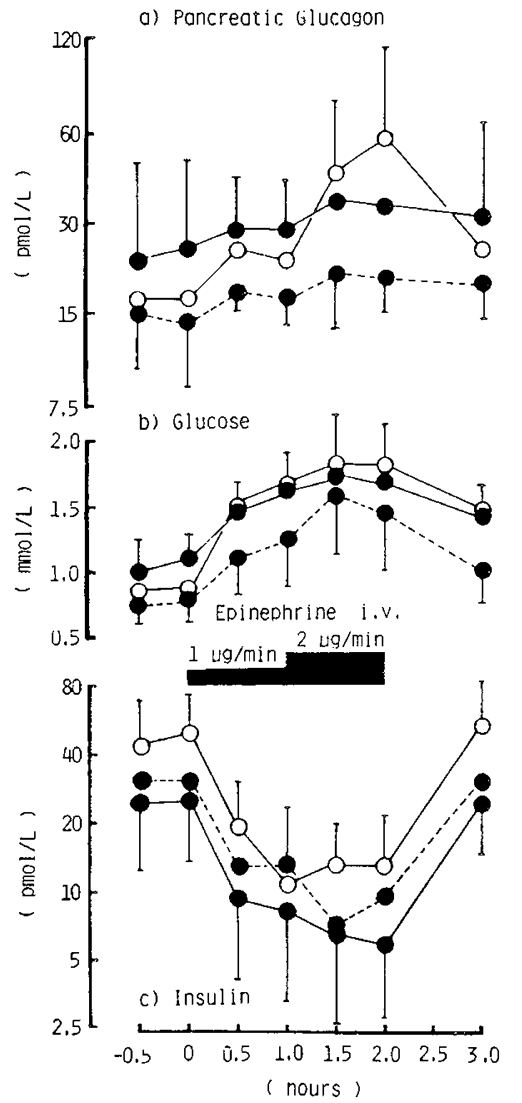

Fig. 3. The effect of i.v. epinephrine infusion on mean \pm SD plasma concentrations of $a$ ) pancreatic glucagon, $b$ ) glucose, and $c$ ) insulin in chronically cannulated fetal lambs $24 \mathrm{~h}$ before $(\mathrm{O} \longrightarrow$; $n=8)$, then $5 \pm 1 \mathrm{~d}$ after $(\longrightarrow ; n=8)$, and again $10 \pm 1 \mathrm{~d}$ after $(--\longrightarrow$ $n=7)$ starting i.v. ritodrine infusion $(10 \mu \mathrm{g} / \mathrm{min})$ to the fetus. Plasma insulin and glucagon are plotted as logarithms.

not indicative of major decreases in response to repeated shortterm epinephrine infusions as used in these experiments. Indeed, increases in plasma glucose and FFA during epinephrine infusion in these fetuses tended to be greater and more clearly distinct than the responses in ritodrine-treated fetuses (data not shown).

Changes in fetal heart rate and blood pressure during epinephrine infusion were also influenced by prolonged ritodrine infusion. Although both absolute values and responses for individuals were variable, both the initial increase in blood pressure and the decline in heart rate during the $1 \mathrm{st} 15 \mathrm{~min}$ of epinephrine infusion were significantly greater $(p<0.025$ by $t$ test) during prolonged ritodrine infusion (Fig. 4). Subsequent changes in heart rate and blood pressure of ritodrine-treated fetuses were similar to those observed during the initial control infusions.

Calculation of the mean value for each of the measured responses to epinephrine as a percentage of the initial basal value (equivalent to an integrated response to epinephrine) (Fig. 5) permits comparison of the extents to which prolonged ritodrine infusion selectively decreased or abolished responses to epinephrine. The greatest effects of prolonged ritodrine were on response parameters regulated by $\beta$-adrenergic receptor mechanisms i.e. plasma FFA, lactate, glucagon, and heart rate. Responses regulated by $\alpha$-receptor mechanisms, e.g. plasma insulin and blood pressure, or subject to more complex regulation, e.g. glucose, were not decreased by prolonged ritodrine administration to the same extent. Comparison of these changes during ritodrine administration with the responses to epinephrine of eight additional age-matched control fetuses showed that they were not simply a consequence of fetal maturation. Indeed, increments in FFA $(550 \%)$ and glucose $(225 \%)$ in these more mature control fetuses were even greater than in the initial control infusions, although
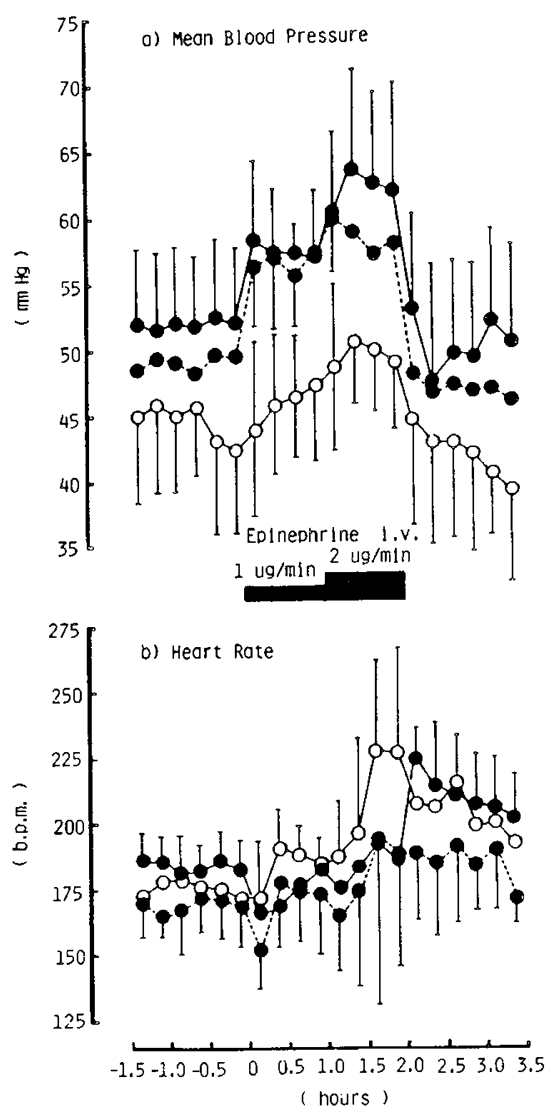

Fig. 4. The effect of i.v. epinephrine infusion on $a$ ) mean arterial blood pressure and $b$ ) mean heart rate in chronically cannulated fetal lambs 24 h before $(\mathrm{O} \longrightarrow ; n=8)$, then $5 \pm 1 \mathrm{~d}$ after $(\longrightarrow ; n$ $=8)$, and again $10 \pm 1 \mathrm{~d}$ after $(--\bullet ; n=7)$ starting i.v. ritodrine infusion $(10 \mu \mathrm{g} / \mathrm{min})$ to the fetus. Values shown are means $\pm \mathrm{SD}$ of continuous records averaged over 15 -min periods.

other responses did not differ significantly from those in the initial control study (data not shown).

\section{DISCUSSION}

The observations reported here confirm and extend earlier observations $(6,8)$ that prolonged ritodrine infusion into fetal lambs in utero causes important changes, lasting $48-72 \mathrm{~h}$, in fetal heart rate and in the plasma concentration of several metabolites and hormones, consequent to activation of $\beta$-adrenergic receptors in a wide variety of tissues. As could be expected from earlier observations of the action of catecholamines in fetal lambs (14), ritodrine administration resulted in a considerable increase in the mobilization of FFA, in addition to the previously reported changes in glucose, lactate, and insulin concentrations.

The experiments reaffirm the severe decrease in fetal arterial oxygen saturation observed by Warburton (8) and in our earlier study (6). Although the cause of this remains uncertain and decreased placental oxygen transfer cannot be excluded, the lack of consistently significant increases in fetal $\mathrm{PCO}_{2}$ at this time (6) suggests that increased oxygen consumption, as observed during norepinephrine infusion (18) or prolonged hyperglycemia and hyperinsulinemia $(9,10)$, is more likely than decreased placental exchange, as discussed earlier (6). However, although the increased oxygen requirement does not exceed the diffusing capacity of the placenta during short-term norepinephrine infusions (18), it appears that this does occur during prolonged ritodrine infusions, with their accompanying hyperglycemia and hyperinsulinemia. However, beyond $72 \mathrm{~h}$ of ritodrine infusion, fetal oxygenation and the other parameters return to the normal 


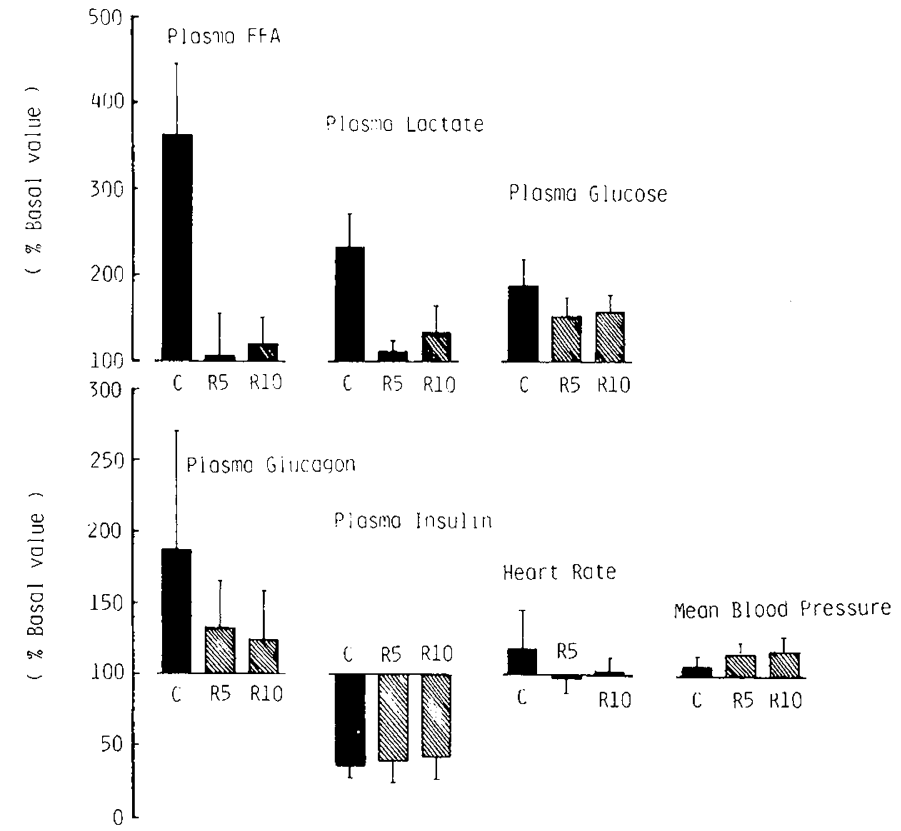

Fig. 5. A comparison of overall responses (mean $\pm \mathrm{SD}$ ) in plasma concentrations of FFA, lactate, glucose, glucagon, and insulin, heart rate, and mean arterial blood pressure during 2-h infusions of epinephrine in fetal lambs before $(C ; n=8)$ or during prolonged ritodrine infusions ( 10 $\mu \mathrm{g} / \mathrm{min})$ for $5 \pm 1(R 5 ; n=8)$ or $10 \pm 1(R 10 ; n=7) \mathrm{d}$. Mean values for the period $0-120 \mathrm{~min}$ of infusion are expressed as a percentage of preinfusion control values.

range, confirming that substantial tachyphylaxis to the drug occurs during prolonged administration.

The rate of ritodrine infusion chosen for use in these investigations, $10 \mu \mathrm{g} / \mathrm{min}$ of $2.86 \mu \mathrm{g} / \mathrm{kg} / \mathrm{min}$, although higher than that used in our earlier study (6), was still within the weight-corrected dose range for pregnant women (19) and resulted in similar changes in the fetuses, with no evidence that the higher dose greatly altered the length of the period before tachyphylaxis occurred. It should be kept in mind, however, that the changes observed in these investigations are not necessarily directly comparable to those that might occur in the human fetus during tocolysis with ritodrine. In that situation, direct actions of ritodrine within the fetus would be additional to those resulting from altered placental nutrient fluxes caused by disturbances to maternal metabolic homeostasis in the early stages of drug administration. During our present investigation, there were no changes in maternal metabolism comparable to those observed during ritodrine administration to the ewe (5).

The epinephrine infusion rates used to assess the influence of prolonged $\beta$-adrenergic agonist infusion on fetal responsiveness to endogenous catecholamines were chosen initially for comparability with rates used by Jones and Ritchie $(13,14)$ to simulate plasma epinephrine concentrations observed in hypoxemic fetuses. Comparison with the more recent observations of Padbury et al. (16) suggests that the lower dose $\left(\sim 0.28 \mu \mathrm{g} / \mathrm{kg} \cdot \mathrm{min}^{-1}\right)$ would establish plasma epinephrine concentrations of $\sim 1000 \mathrm{pg} /$ $\mathrm{mL}$, whereas the higher dose during the 2 nd hour of infusion would establish concentrations in the range of $2500-3000 \mathrm{pg} /$ $\mathrm{mL}$; both concentration ranges are well above the thresholds established by Padbury et al. (16) for responses in all the parameters measured during our present study. The changes observed during the initial control studies, before ritodrine infusion, confirm this. However, the responses of ritodrine-treated fetuses to short-term epinephrine infusion provide clear evidence (Fig. 5) that, despite the apparent normality of basal cardiovascular and plasma metabolic parameters, continued infusion of ritodrine had either promoted profound desensitization of $\beta$-adrenergic receptor mechanisms to stimulation by endogenous catechol- amines such as epinephrine as well as by ritodrine itself or, alternatively, had resulted in a widespread depletion of substrate stores. Warburton et al. (7) reported a marked depletion of hepatic glycogen after $24 \mathrm{~h}$ of ritodrine administration to fetal lambs, and markedly reduced muscle glycogen stores have been observed in a number of studies on postnatal animals treated with $\beta$-agonist drugs (20). Substrate depletion, therefore, may be an important contributor to the loss of sensitivity observed. However, the clear association of decreased sensitivity to ritodrine in all responses measured during prolonged infusion of the drug, with the loss of responsiveness to acute epinephrine challenge in metabolic and endocrine responses dependent on $\beta$ receptor activation while $\alpha$-receptor mediated responses remain unchanged, argues for involvement of $\beta$-receptor desensitization. The marked reduction in $\beta$-adrenergic receptor populations of fetal lung tissue after only $24 \mathrm{~h}$ of ritodrine infusion (12) provides further support for this interpretation. Whatever the cause, the selective loss of responsiveness to epinephrine was already evident within $5 \mathrm{~d}$ after the start of infusion and was unchanged after $10 \mathrm{~d}$ of drug infusion, despite apparently normal basal plasma hormone and metabolite concentrations after the 1st 48$72 \mathrm{~h}$ of treatment. The results suggest that threshold concentrations of epinephrine required to stimulate some of the measured responses must have increased greatly relative to the values reported by Padbury et al. (16). Some important metabolic changes consequent to activation of $\beta$-adrenergic receptors by physiologic concentrations of epinephrine in term fetuses have been virtually abolished by the continued ritodrine infusion, whereas events mediated by $\alpha$-adrenergic mechanisms remain unchanged, or, like the change in blood pressure, may be enhanced by the loss of $\beta$-adrenergic tone. The consequences of prolonged administration of a $\beta$-agonist such as ritodrine seem more akin, therefore, to those of chronic $\beta$-adrenergic receptor blockade than to promotion of $\beta$-adrenergic activity. The similarity of all the responses to epinephrine in ritodrine-treated animals to responses in fetal lambs given epinephrine with $\beta$ blocking drugs (13-15) is striking.

Although desensitization of myometrial $\beta$-adrenergic receptors by prolonged $\beta$-agonist infusion is well recognized $(21,22)$, there is little information on the metabolic or endocrine changes in human fetuses during prolonged tocolysis with $\beta$-adrenergic drugs. Fetal heart rates, like those in the mother, increase paralle to the dose of ritodrine administered during the 1 st $24 \mathrm{~h}$ of treatment $(2,3)$. However, just as in the sheep fetus, attenuation of maternal and fetal tachycardia occurs during more prolonged administration $(2,3)$, indicating tachyphylaxis to ritodrine. This may protect fetuses from the potentially dangerous consequences of worsening lactacidemia and hypoxemia (6), the continued depletion of hepatic (7) and muscular (20) glycogen stores, or the more frequent occurrence of serious cardiovascular complications (23), but it is achieved at the cost of reduced $\beta$-adrenergic responsiveness. Catecholamines play a very important role in adaptation to the changes in physiologic state during acute hypoxemia and asphyxia (24) or at birth $(24,25)$. Indeed, at birth, both adaptation of the lungs to air breathing (26) and the switching on of thermogenesis within brown fat (27), like many other adaptive changes at this time, depend critically on $\beta$ adrenergic mechanisms. Decreased $\beta$-adrenergic receptor responsiveness could have important consequences for this adaptation.

Despite these findings, their relevance to use of $\beta$-agonists for tocolysis in human pregnancy remains uncertain. Although there has been concern about possible cardiovascular complications in the fetus from $\beta$-sympathomimetic therapy for tocolysis (23) and effects of $\beta$-agonists on the incidence or respiratory distress and perinatal hypoglycemia $(1,28)$ have been reported, the incidence of long-term complications appears low (28). However, adverse effects of $\beta$-receptor blocking drugs in the human infant have also been a source of concern $(29,30)$, so our results suggest that caution should be exercised in the passive administration of $\beta$ adrenergic drugs such as ritodrine to the fetus over prolonged 
periods of time. Such infants should clearly be provided with the same level of care as that recommended for infants from $\beta$ blocked pregnancies (30).

Acknowledgments. The authors thank R. Borrett, Frances Knight, and J. Shepherd for their valuable assistance in laboratory analytical work and in the preparation and care of animals used for these experiments.

\section{REFERENCES}

1. Gross TL, Kuhnert BR, Kuhnert PM, Rosen MG, Kazzi NJ 1985 Maternal and fetal plasma concentrations of ritodrine. Obstet Gynecol 65:793-797

2. Caritas SN, Lin LS, Toig G, Wong LK 1983 Pharmacodynamics of ritodrine in pregnant women during pre-term labor. Am J Obstet Gynecol 147:752759

3. Hill WC, Katz M, Kitzmiller JL, Gill PJ 1985 Continuous long-term intravenous $\beta$-sympathomimetic tocolysis. Am J Obstet Gynecol 152:271-274

4. Fujimoto S, Akahane M, Uzuki K, Inagawa A, Sakai K, Sakai A 1984 Placental transfer of ritodrine hydrochloride in sheep. Int J Gynaecol Obstet 22:269274

5. Bassett JM, Burks AH, Levine DH, Pinches RA, Visser GHA 1985 Maternal and fetal metabolic effects of ritodrine. Obstet Gynecol 66:755-761

6. Bassett JM, Hanson C, Weeding CM 1989 Metabolic and cardiovascular changes during prolonged ritodrine infusion in fetal lambs. Obstet Gynecol 73:117-122

7. Warburton D, Parton L, Buckley S, Cosico L, Saluna $\Upsilon 1987$ Effects of $\beta-2$ agonist on hepatic glycogen metabolism in the fetal lamb. Pediatr Res $24: 330-332$

8. Warburton D, Parton L, Buckley S, Cosico L, Saluna T 1987 Effects of beta-2 agonist on tracheal fluid flow, surfactant and pulmonary mechanics in the fetal lamb. J Pharmacol Exp Ther 242:394-398

9. Philipps AF, Dubin JW, Matty PJ, Raye JR 1982 Arterial hypoxemia and hyperinsulinemia in the chronically hyperglycemic fetal lamb. Pediatr Res $16: 653-658$

10. Milley JR, Rosenberg AA, Philipps AF, Molteni RA, Jones MD, Simmons MA 1984 The effect of insulin on ovine fetal oxygen extraction. Am J Obstet Gynecol 149:673-678

11. Warburton D, Parton L, Buckley S, Cosico L, Saluna T 1987 Effects of beta-2 agonist on metabolic regulation in the fetal lamb lung. J Pharmacol Exp Ther 242:389-393

12. Warburton D, Parton L, Buckley S, Cosico L, Enns G, Saluna T 1988 Combined effects of corticosteroid, thyroid hormones and $\beta$-agonist on surfactant, pulmonary mechanics and $\beta$-receptor binding in fetal lamb lung. Pediatr Res 24:166-170
13. Jones CT, Ritchie JWK 1978 The cardiovascular effects of circulating catecholamines in fetal sheep. J Physiol 285:381-393

14. Jones CT; Ritchie JWK 1978 The metabolic and endocrine effects of circulating catecholamines in fetal sheep. J Physiol 285:395-408

15. Sperling MA, Christensen RA, Ganguli S, Anand R 1980 Adrenergic modulation of pancreatic hormone secretion in utero: studies in fetal sheep. Pediatr Res 14:203-208

16. Padbury JF, Ludlow JK, Ervin MG, Jacobs HC, Humme JA 1987 Thresholds for physiological effects of plasma catecholamines in fetal sheep. Am J Physiol 252:E530-E537

17. Bassett JM, Burks AH, Pinches RA 1983 Effects of intravenous glycine infusion on plasma glucagon, insulin and metabolite concentrations in lambs before and after birth. J Dev Physiol 5:51-61

18. Lorijn RHW, Longo LD 1980 Norepinephrine elevation in the fetal lamb: oxygen consumption and cardiac output. Am J Physiol 239:R115-R122

19. Barden TP, Peter JB, Merkatz IR 1980 Ritodrine hydrochloride: a betamimetic agent for use in preterm labor 1. Pharmacology, clinical history, administration, side effects and safety. Am J Obstet Gynecol 56:1-6

20. Williams PEV 1987 The use of $\beta$-agonists as a means of altering body composition in livestock species. Nutr Abs Rev 57:454-464

21. Berg G, Andersson GG, Ryden G $1985 \beta$-adrenergic receptors in human myometrium during pregnancy: changes in the number of receptors after $\beta$ mimetic treatment. Am J Obstet Gynecol 151:392-396

22. Casper RF, Lye SJ 1986 Myometrial desensitization to continous but not to intermittent $\beta$-adrenergic agonist infusion in the sheep. Am J Obstet Gyneco 154:301-305

23. Katz VL, Seeds JW 1989 Fetal and neonatal cardiovascular complications from $\beta$-sympathomimetic therapy for tocolysis. Am J Obstet Gynecol 161:1-

24. Jones CT 1980 Circulating catecholamines in the fetus, their origin, actions and significance. In: Parvez H, Parvez S (eds) Biogenic Amines in Development. Elsevier/North Holland Biomedical Press, Amsterdam, pp 63-86

25. Hagnevik K, Faxelius G, Irestedt L, Lagercrantz H, Lundell B, Persson B 1984 Catecholamine surge and metabolic adaptation in the newborn after vaginal delivery and caesarian section. Acta Paediatr Scand 73:602-609

26. Ballard PL 1986 Hormones and lung maturation. Monogr Endocrinol 28:239 277

27. Cannon B, Nedergaard J 1982 The function and properties of brown adipose tissue in the newborn. In: Jones CT (ed) Biochemical Development of the Fetus and Newborn. Elsevier Biomedical Press, Amsterdam, pp 697-730

28. Kazzi NJ, Gross TL, Kazzi GM, Williams TG 1987 Neonatal complications following in utero exposure to intravenous ritodrine. Acta Obstet Gynecol Scand 66:65-69

29. Kjellmer I 1981 Fetal cardiovascular reactions during labour and asphyxia modified by adrenergic receptor agonists and antagonists. Ciba Found Symp $83 \cdot 310-325$

30. Boutroy MJ 1987 Fetal and neonatal effects of the beta-adrenoreceptor blocking agents. Dev Pharmacol Ther 10:224-231 